\title{
Do cinema à análise do discurso dos media
}

\author{
Teresa Maia e Carmo
}

\author{
Escola Superior de Educação do Instituto Politécnico de Santarém, Portugal
}

\begin{abstract}
How can film be operative in the analysis of media discourse?

From the point of view of the work of analysis, one thing is the object of study (a piece of press, radio, television or digital based) arriving at the hands of the analyst or the student while finished; another thing is that same object considered referring it to the historical, social and personal context in its genesis. We consider that there is an undeniable addition of value when this happens: given our experience of analysis and teaching, this is what we see that film "does".

We want to bring to the discussion two films: "The Post" (Steven Spielberg, 2017) and "All The President's Men" (Alan J. Pakula, 1976). From the point of view of the analysis of the discourse of the media, what approximation to space and objects, to the gestation time of journalistic work, to the very physicality of the process do these two films bring? From the point of view of film, since both refer in different ways to the same epoch - one, directly, once is made three years after the narrated events, as is the case of "All The President's Men '; and another as a 'vintage' movie, therefore, as a reconstitution, with other objects and other bodies, as is the case of "The Post" - what are the differences between one and the other, from the point of view of representation? What, finally, does film document?
\end{abstract}

Keywords: Cinema, Jornalismo, Transmedia, Multimedia, Educação

\section{Introdução:}

Aqui se relata uma experiência didácticopedagógica de aprofundamento das competências de literacia mediática através do cinema. Em tempos de informação caleidoscópica, a plasticidade das fontes de conhecimento é exponencial, mas desorganizada. Através da exploração das relações entre cinema e jornalismo, tentou-se que os alunos compreendessem o que é a atividade jornalística e as suas formas de inscrição na contemporaneidade mediática. Tal objectivo, que até há poucos anos era relativamente simples de atingir, tornou-se um peculiar quebra-cabeças. A razão: os estudantes deixaram de ler jornais. Ou algo que se lhe equipare: o consumo regular de um produto mediático informativo tradicional, mediado por profissionais encartados - os jornalistas - já não faz parte da «dieta de media» dos nascidos no século XXI.

As razões são muitas e a crise dos chamados media tradicionais explica-se por diferentes ordens de razões. Os processos de globalização comunicacional que emergiram do paradigma digital transformaram o conceito de «pessoa informada», valorizando o acesso à informação e não às notícias, numa atitude de produção de conhecimento e acção a partir do cruzamento de todas as fontes mediáticas ao dispor de cada um (Cardoso 2009). O advento do prosumer (Toffler 1980), produtor e simultaneamente consumidor de informação, articulando em rede media de massa e interpessoais, enforma uma "cultura de convergência» (Jenkins 2008) que afectou todos os campos da experiência social, incluindo naturalmente a educação.

Por outro lado, a explosão da auto-edição e a afirmação do «Conteúdo Gerado pelo Utilizador», aliados a uma série de factores como a insustentabilidade do modelo de negócio dos media convencionais - cujos lucros passaram a ser absorvidos pelos grandes distribuidores digitais de conteúdos - e uma crise de credibilidade sem precedentes (Kovach e Rosentiel 2004 e 2010; Mesquita 2013; Fidalgo 2009), transformaram o jornalismo numa actividade com muito «má Imprensa» (Maia e Carmo 2016). Os estudantes manifestam uma atitude de desconfiança perante os «media tradicionais» que consideram sob permanente suspeita de manipulação, enquanto ostentam simultaneamente uma ingénua credulidade na transparência redentora das fontes digitais que aparecem como que por milagre nos seus murais e feeds em circuito fechado das redes sociais, constituindo a sua primordial fonte de informação. «Vi num vídeo, veio de um influencer que sigo».

No contexto da unidade curricular (UC) «Análise do Discurso dos Media» do segundo semestre do primeiro ano da Licenciatura em Produção Multimédia em Educação da Escola Superior de Educação do Instituto Politécnico de Santarém, o presente artigo versa sobre o potencial didáctico e pedagógico do cinema para a prossecução de alguns dos objectivos de aprendizagem (OA) da referida UC. A saber: "conhecer os diferentes discursos mediáticos, nas suas formas de produção, encenação e recepção» (OA2); «produzir um discurso analítico sobre os media» (OA4) e «reflectir criticamente acerca da contemporaneidade mediática» (OA5). Esta caracteriza-se nos tempos mais recentes pela emergência das chamadas «fake news», termo que repudiamos uma vez que tais produções simplesmente não são notícias: apenas falsidades. A sua menção neste contexto relaciona-se com o facto de o assunto ter sido trabalhado com este grupo de estudantes no semestre anterior.

Foi esse o ponto de partida para a prática pedagógica que aqui se descreve. O contexto é o do desenvolvimento das aprendizagens adquiridas em Educação para os Media (UC do semestre anterior), aprofundando a literacia mediática dos estudantes. O conceito de literacia mediática tem feito o seu caminho (Thoman 2003; Livingstone 2003, 2004 a, 2004 b, 2011; Thoman e Jolls 2003) e a definição operatória que aqui adoptamos é a que foi proposta pelos peritos europeus do Media Literacy Expert 
Group. Literacia mediática é, pois, «a capacidade de aceder aos media, de compreender e avaliar de modo crítico os diferentes aspetos dos media e dos seus conteúdos, e de criar comunicações em diversos contextos» (COM 2007).

Este grupo de peritos aponta quatro domínios essenciais, que se interpelam sistemicamente no multidimensional conceito de literacia mediática: aceder, compreender, avaliar e criar. $\mathrm{O}$ que corresponde em larga medida às três grandes dimensões enunciadas por outros especialistas: a dimensão técnica, a crítica e a criativa (Euromeduc 2009; EAVI, 2009, 2011). Seguindo este quadro conceptual como guia para o ensino/aprendizagem tratava-se, pois, de dar acesso (primeira dimensão) a uma fonte de informação riquíssima (a história do jornalismo no cinema), treinando sobretudo os domínios do "compreender e avaliar», como base para o "criar», um dos mais fortes propósitos da Produção Multimédia, que a Licenciatura enfatiza.

Ora, actualmente, o jornalismo - ou seja, a informação produzida num enquadramento profissional fortemente regulado normativamente tornou-se muito mais que um produto meramente textual. Tornou-se gráfico, infográfico, iconográfico, em suma, multimodal (Peltzer 1992).

Aproveitando a prática comum já consolidada entre os aprendentes deste zapping formativo e informativo, a abordagem à análise do discurso da Imprensa em particular (não a televisão, a rádio ou os media digitais) através do cinema, apesar de aparentar ser uma estratégia pedagógica old school revelou-se de grande valia.

A análise de discurso, designação comum a múltiplas formas de analisar a relação entre o sentido e a linguagem, bem como as suas repercussões sociais e políticas (metodologia muito utilizada nas Ciências Sociais, Linguística ou Estudos dos Media), não apresentando um método uniforme de desconstrução e reconstrução dos textos (que é o que se processa em qualquer análise) trata da importância do discurso na construção social da realidade (Carvalho 2000).

O cinema é um médium (e muito mais que isso). A Imprensa é um médium (e muito mais que isso). Ambos constroem realidades, cada um na sua especificidade técnica e artística. As relações entre ambas constituem um namoro antigo que vale a pena dar a conhecer aos estudantes.

\section{Desenvolvimento:}

«O que é que une os povos? Exércitos? Ouro? Bandeiras? Histórias. Não há nada mais poderoso no mundo do que uma boa história»

Tyrion Lannister, Guerra dos Tronos

São profundas as relações entre cinema e jornalismo. Os dois media, um mais antigo que o outro, interpelam-se mutuamente desde o início.

A Imprensa, que vem do século de Gutenberg, narrou entusiasticamente o nascimento do cinema há um pouco mais de um século. O Cinema enforma algumas das práticas jornalísticas desde o início. Os irmãos Lumière foram os primeiros repórteres de imagem da História, colhendo imagens um pouco por todo o mundo que mais tarde passariam nas salas de cinema como "actualidades». Méliès reconstitui grandes acontecimentos da época (L'Affaire Dreyfuss, Catastrophe du ballon Pax, Congrès des Nations en Chine, entre outros). Rapidamente a figura do repórter se torna um personagem recorrente do cinema, chegando na opinião de muitos a formar um verdadeiro género - o «cinema de jornalismo».

Não havendo abundante bibliografia sobre o tema, seguimos em primeiro lugar o interessante debate promovido pelos Cahiers du Cinéma no Festival de Locarno, que resultou no livro "Print the Legend Cinèma et Journalisme», agregando colaborações de cineastas, jornalistas, filósofos, críticos e teóricos do cinema (Gosetti e Frodon 2004).

Como afirma Frodon, o cinema e a Imprensa

têm imenso em comum. Separam-nos diferenças fundamentais. Não apenas as suas relações existem desde que o mais jovem, o cinema, nasceu, mas estas relações já lá estavam (...) desde o início dos tempos. Desde que existem estes dois gestos fundadores do humano: contar histórias, mostrar o mundo (Frodon 2004, 13).

O autor, sustentando que o «cinema de jornalismo» é considerado por muitos um sub-género (voltaremos adiante a esta questão) do «film noir» que prosperou em Hollywood até aos anos 50 do século XX, enumera alguns dos pontos comuns e divergentes entre os dois media. Em comum, além de serem media de massas, têm o facto de ambos não apenas darem imagens do mundo, mas construírem também uma imagem do mundo. No caso da Imprensa pelo conjunto de decisões que implica a fabricação de um jornal, no do cinema todos os gestos e resoluções de montagem.

Num e noutro caso existe a afirmação, sempre em parte fundada, sempre em parte contestável, de uma «reprodução» do real, em que o profissionalismo e a deontologia são supostos ser os garantes, e em que a natureza técnica do registo cinematográfico pelas máquinas que utiliza se quer a atestação. Sabemos desde sempre que isto se trata não de um facto, mas de um horizonte para o qual tendem, ou deveriam tender uma e outra prática (Frodon 2004, 14)

A célebre frase «when the legend becomes a fact, print the legend» é posta na boca de um jornalista... por um cineasta (O Homem que Matou Liberty Valance, John Ford, 1961). Para lá da muita literatura sobre este diálogo e o cinema de Ford, interessanos aqui reter a capacidade que ambos, Imprensa e Cinema, têm de criar lendas, a partir e apesar dos factos. O realizador Abbas Kiarostami referese a outros aspectos que jornalismo e cinema têm em comum, sublinhando que ambos tem o mesmo objectivo: mostrar a realidade à nossa volta. 
O cinema possui, no entanto, uma vantagem. Enquanto a peça jornalística se perde no dia seguinte na engrenagem da informação, o cinema não desaparece com o tempo, pode utilizar uma linguagem mais profunda, pode aspirar a ultrapassar esse carácter efémero (...) ambos tentam mostrar uma verdade das coisas e dos seres. Porém o cineasta possui unicamente uma metade da verdade possível. A outra metade encontra-se nas mãos do espectador que reage face á imagens que lhe são propostas (...) Estou convencido de que o bom cinema se enraíza na realidade e o mau cinema é falso por natureza (Kiarostami 2004, 26).

No jornalismo a questão da verdade é discutida há muito. O mito da objectividade jornalística converteuse nisso mesmo, mercê de uma longa linha de debate no seio dos estudos dos media. Tal não implica, porém, que uma e outra (verdade e objectividade) devam distanciar-se ou anular a vontade da primeira por simples desistência. A natureza de construção (da e a partir da realidade) implícita no jornalismo é aceite e sublinhada pelo mítico repórter do Caso Watergate, Carl Bernstein, que fala da «melhor versão que podemos obter da verdade».

Uma boa reportagem, quer seja sobre desporto, a actualidade municipal, a presidência ou a cultura, é sempre a melhor versão que podemos obter da verdade (...) E, sim, a verdade existe. A melhor versão que podemos obter da verdade existe. Parece-me que este conceito de verdade é subjectivo, que existe um mito de objectividade na Imprensa americana em particular e que, de certa maneira, a meta é ser-se objectivo. Não acredito nisso, porque se há gesto bem subjectivo é o de decidir o que é e não é informação. Não vamos fazer um serviço com a pretensão de sermos objectivos. Temos a responsabilidade de sermos justos e judiciosos, metódicos e precisos, perspicazes e inventivos, mas isso é bem diferente da objectividade, porque esta é muito mais uma questão científica que humana (...) Cada medium em particular - parece-me - tem uma força visceral própria. Seja a palavra impressa, a fotografia ou o cinema. $E$ todos têm em comum uma capacidade de transmitir a verdade. (Bernstein 2004, 23)

Desde The Power of the Press (Van Dyke Brooke 1909), passando por Citizen Kane (Orson Welles 1931) a The Post (Spielberg 2017) são incontáveis os chamados «filmes de jornalismo» ou «de jornalistas». Em 1993 a Cinemateca Portuguesa organizou com o jornal Expresso um ciclo intitulado Cinema e Jornalismo em cujo catálogo (Bénard da Costa et al 1993) Manuel Cintra Ferreira coligiu numa lista a que chamou «Jornalistas no Cinema» 773 títulos de filmes estreados entre 1909 e 1992, entre eles quatro títulos portugueses. Cartas na Mesa (Rogério Ceitil 1973), O Meu nome é... (Fernando Matos Silva 1976), O Lugar do Morto (António-Pedro Vasconcelos 1984) e Repórter X (José Nascimento 1985).

Christa Berger, autora do livro «Jornalismo no Cinema (2002), listou 785 filmes, destacando a maioria norte-americana, que explica pelo facto de ser a a indústria que conseguiu traduzir com maior sucesso o imaginário coletivo que associa a profissão à investigação, à aventura, à independência, ao arrojo e, igualmente, ao cinismo, à falta de escrúpulo, à arrogância. (Berger 2002,17)

Porque na imagem do jornalista tratada pelo cinema existe de tudo. Os filmes acomodam as muitas e contraditórias percepções e expectativas do público perante a Imprensa. Para Howard Good a imagem do jornalista, sempre retratado como uma personagem ambígua, «que tanto promove a luz como a escuridão, a crueldade e a justiça, o individualismo e integração social» (Good 1989, 24), divide-se em três grandes sub-tipos: o correspondente de guerra; o repórter sem escrúpulos apenas fixado na obtenção de uma «cacha» em proveito próprio; o jornalista de investigação que desmonta uma conspiração.

Quer estejam a apanhar bandidos ou a cobrir uma guerra, os jornalistas aparecem quase sempre presos de dilemas existenciais. Lutam com questões como a verdade e a ficção, objectividade e subjectividade, compaixão e distância (Good 1989, 16)

num reflexo da imagem do profissional que já vinha sedimentada da literatura popular dos finais do século XIX (Good 1989, 9). O autor fundamenta esta diversidade de tipos, histórias e ambientes na constatação de que

os realizadores não lideram a opinião pública; geralmente seguem-na, ou tentam. Os padrões narrativos do género filme de jornalismo são espelhos de, ou metáforas para - a relação entre o público e a Imprensa, as suas esperanças arruinadas, os seus desejos desesperados e promessas ambíguas (Good 1989, 2).

Bill Mahon (1994) elenca quatro estereótipos de jornalistas na produção de Hollywood: os «santos», como os dois repórteres de Os Homens do Presidente, éticos e empenhados na busca do verdade e numa investigação séria; os «silhuetas», jornalistas aos magotes, em corredores apinhados ou à porta de tribunais a bombardear os protagonistas com perguntas em atropelo, «servem só para fazer avançar a história e desaparecem»; os "santos de auréola impura» que cometem erros e uma ou outra vilania em busca da informação, mas estão animados das melhores intenções, e por fim «os monstros», como a personagem de Kirk Douglas Ace in the Hole (Billy Wilder, 1952), sem qualquer tipo de escrúpulos, um «tipo» muito encenado nos anos mais recentes do cinema.

$\mathrm{Na}$ verdade, desde o início desta representação do jornalista no cinema, o lado heróico ou vilão da figura esteve sempre presente. Desde os clássicos do género já mencionados, mas também em muitos outros (Corrupção do Poder, Robert Rossen 1949; O Grande Carnaval, Billy Wilder 1951; A Última Ameaça, Richard Brooks 1952; Loura Platinada, Frank Capra 1931; A Calúnia, Sidney Pollack 1981). A grande ruptura na versão "Tintim» do repórter made in Hollywood, com a sua aura de coragem e integridade, veio com The 
Front Page, adaptação da peça teatral da Broadway de Hecht e MacArthur, nas suas várias versões (Lewis Milestone 1931, O Grande Escândalo, de Howard Hawks 1955, e a de Billy Wilder, Primeira Página, 1974) em que o cinismo insidioso e o desencanto se colam de forma tão perene à figura do jornalista como as qualidades de pureza e integridade igualmente incensadas noutros filmes.

Mais do que uma figura digna de admiração ou repulsa, o profissional possui «um rosto, uma identidade e um aspecto meramente humanos e, portanto, ele está sujeito aos revezes da vida e da profissão», afirma Pereira (Pereira 2003, 5).

Lisandro Nogueira aponta que

ao escolher o jornalista como personagem o cinema quer acompanhar os passos rápidos da modernização. As afinidades entre cinema e jornalismo começam na ideia da "transparência do registro" (...). «tanto o jornalismo quanto o cinema clássico propugnam trazer a verdade à tona. Isto é, deixar transparente aquilo que é nebuloso, opaco». (...) o pressuposto da verdade das imagens e das notícias as faz caminhar lado a lado. O jornalista como personagem é a confirmação de uma aposta na verossimilhança das imagens. Ele dá credibilidade porque é o porta-voz de uma "vontade de esclarecer". (Nogueira 2007)

O mesmo autor lembra, ainda, que os dois media partilham a mesma raiz.

O modelo narrativo romanesco influenciou fortemente a maneira de o cinema americano contar histórias com imagens em movimento. O mesmo modelo marcou profundamente o padrão americano de apresentação da notícia. (Nogueira 2007)

Além deste aspecto temos a predominância da acção (busca da notícia e desenvolvimento do conflito na narrativa) e o desencadear de uma história com princípio, meio e fim.

A reportagem jornalística obedece ao padrão de iniciar uma pequena história, contá-la, e apressar o seu fim com um desfecho feliz ou espetacular. $O$ melhor exemplo encontra-se no telejornalismo.

Quanto à questão de saber se existe ou não um género "cinema de jornalismo», as dificuldades são enunciadas por Richard R. Ness. Desde logo, porque a personagem do jornalista encontra-se em diferentes géneros. No western (Dodge City, M. Curtiz, 1939; O Homem que Matou Liberty Valance, John Ford, 1961), no filme de guerra (Story of G.I. Joe, W. A. Wellman, 1945, We were Soldiers, R. Wallace, 2002), em comédias românticas (Libeled Lady. J. Conway, 1936), em filmes de terror (Mistery of the Wax Museum, M. Curtiz, 1933, The Ring, G. Verbinsky, 2002) e até em musicais (High Society, C. Walters, 1956). O autor ressalta que, em primeiro lugar, é preciso distinguir entre filmes que têm jornalistas como personagens e aqueles que tratam especificamente de questões ligadas à Imprensa e ao seu papel na sociedade.

Ness empreende, então, a defesa da existência de um verdadeiro género, que analisa em termos de iconografia (vestuário, acessórios, ambientes), personagens e narrativa, segundo o modelo «conflito/ resolução». (Ness 2004, 47) Quanto à iconografia refere a aparência sempre algo desleixada da figura do/a jornalista, como caracterizador de uma indiferença face às aparências. Os homens de fatos amarrotados, as mulheres de calças ou fatos saia-casaco algo masculinos «já se tinham tornado um cliché nos finais dos anos 50» (Ness 2004, 51). Os utensílios associados à profissão, como o bloco de notas, o gravador, câmaras fotográficas, telefones, máquinas de escrever e computadores. $\mathrm{E}$ comportamentos como o consumo de álcool, tabaco ou jogo, associados ao décor da redacção, sempre em ebulição sonora e vai-vem de personagens, além do som ensurdecedor das rotativas e dos pregões dos ardinas, quando ainda os havia.

Quanto ao tratamento das personagens, Ness elenca uma série de características observáveis no que considera serem os filmes do género, das quais se destacam a natureza algo outsider do jornalista, como alguém que trabalha sempre com algum desdém pelas estruturas hierárquicas, cuja vida privada é quase sempre instável ou inexistente (Ness 2004, 85). Tal caminho (iconografia, personagens e narrativa) foinos bastante útil na exploração da linha temática que enunciámos, como se relatará nas conclusões.

Quanto ao que separa a Imprensa do Cinema, poder-se-iam apontar um sem número de aspectos. Destacamos os que aponta Frodon quando frisa que a Imprensa vive dentro de uma lógica de difusão, o Cinema numa outra de produção. As «actualidades filmadas» anteciparam a televisão, mas desde que esta «libertou» o cinema da sua actividade estritamente jornalística como «construtor dos imaginários colectivos modernos», a natureza compósita do cinema afirmou-se.

Esta apela ao trabalho do negativo, a parte da sombra, se não a parte maldita. A ambivalência fecunda própria do cinema relaciona-se com aquilo que cedo começou a ser pensado como o papel decisivo do fora de campo. Resulta da inscrição do cinema simultaneamente no grande labor da fabricação do visível, tal como ele é declinado desde a segunda metade do século XIX e no imenso empreendimento que é a relação dos homens com o invisível, e essa, data desde o princípio dos tempos (Frodon 2004, 15).

Por outro lado, o cinema é uma arte...

...a sétima, o que é o contrário de um media. A pretensão de um media é contruir a visibilidade, fazer desparecer a sombra. Os media trabalham num universo regido pela noção de "segredo», do que está escondido e é preciso trazer à luz. As artes trabalham num universo regido pela noção de «mistério», não se trata de o desvelar (não há nada a desvelar), trata-se de se lhe aproximar, de Ihe experimentar as vertigens, as ressonâncias. (Frodon 2004, 15) 
As aproximações entre cinema e jornalismo são múltiplas e dispersam-se por geografias e tempos muito diversos. Os filmes sobre jornalismo fazem parte da história do cinema e continuam a ser produzidos. Como diz Nogueira (2003) «O cinema é o locus privilegiado para se compreender o jornalismo e a sociedade em que ambos se inserem». A verdade é que

a estreia regular de filmes sobre jornalismo com considerações morais acerca do papel dos media na sociedade significa que o filme de jornalismo continua pertinente para os espectadores de hoje (...) Na época da imagem digital e do ciberespaço, não somente a verdade, mas a própria natureza da realidade tornaram-se negociáveis (Richard R. Ness, 91)

Hoje assiste-se a um particular regresso do tema com a chegada de Trump à presidência americana. A sua confessa hostilidade pelos media e as embrulhadas em que o seu gabinete se envolve amiúde, trazendo à agenda expressões tão extraordinárias como «factos alternativos» (na memorável justificação da sua conselheira de imprensa para falsear o número de pessoas presentes na tomada de posse presidencial) e a frequência com que o próprio presidente apelida de "fake news» toda a informação que the é adversa, confundindo o que tem sido a epidemia da proliferação das «fake news» propiamente ditas, ou seja, desinformação concertada e propagada através das redes sociais, trouxeram o jornalismo de volta à agenda social contemporânea.

\section{Resultados:}

A atividade proposta aos estudantes partiu muito do interesse que o tema da desinformação nas redes sociais suscita actualmente, a par da verificação da importância do jornalismo de qualidade para a consolidação das democracias.

Abordar o jornalismo a partir do cinema e da personagem do jornalista a partir da forma (sem ignorar o conteúdo, que serviu para reflectir sobre o contexto histórico dos acontecimentos e sua relação com a actualidade) foi uma maneira de aprofundar o debate sobre os filmes através da sua estrutura narrativa e tratamento técnico e artístico, utilizando as tradicionais ferramentas de análise de discurso aplicadas à imagem cinematográfica.

A observação do tempo de gestação do trabalho jornalístico, os espaços em que estes profissionais se movimentam, a forma como se vestem, os objectos de época, técnicos e decorativos, a orgânica de uma redacção vista por um realizador contemporâneo dos factos (Pakula) e por outro à distância de mais de três décadas (Spielberg), serviu para incrementar tanto a literacia audiovisual como a literacia mediática deste grupo de estudantes.

O cinema traz a experiência de metafenomenologia da percepção da actividade jornalística na sua fisicalidade (um corpo sentado, a fazer telefonemas e tirar notas). Uma imersão na vida de personagens realistas, com os seus imponderáveis, objectos concretos (máquinas de escrever, papel, e não computadores, máquinas fotográficas analógicas) e tempos apertados de descoberta e produção, em contextos socioculturais e históricos específicos, deu aos estudantes uma aproximação mais rica e humana da produção mediática.

Através do que o cinema documenta, trazendo o tempo dos media através do cinema, realizaramse várias sessões de debate e enquadramento, tendo os estudantes elaborado uma reflexão crítica sobre o assunto, em que foi visível o interesse na aprendizagem em questão mas também nas conexões que fizeram com outros temas de interesse da actualidade, como a descriminação com base no género (Katherine Graham era mulher, num tempo em que as mulheres não dirigiam jornais).

Foram referidas as dificuldades de recepção no filme mais antigo (Os Homens do Presidente) com tempos longos no desenvolvimento da aç̧ão, relativamente à familiaridade contemporânea do ritmo de Spileberg (The Post), mais sintético e incisivo. Nas palavras de um aluno:

\begin{abstract}
Importa ainda referir, que apesar de apresentarem muitas semelhanças, os filmes apresentados têm simultaneamente grandes diferenças entre si. O filme "The Post" foi realizado mais recentemente que o filme "Os Homens do Presidente", apresentando uma melhor qualidade cinematográfica, como a qualidade da imagem, efeitos sonoros, matérias e argumentação. Este apresenta uma forma mais apelativa de visionamento para o espectador, visto que é bastante fácil de reter toda a informação, contrariamente ao filme "Os Homens do Presidente", que transmite uma imensidão de informação numa fração muito pequena de tempo, sendo este bastante complicado para os espectadores reterem qualquer informação, tornando-se mais entediante de se observar para os mesmos».
\end{abstract}

Ou de outro:

Através do visionamento dos filmes em apreço na sala de aula, pode-se concluir que ambos apresentam simultaneamente uma proximidade, sendo que ambos abordam a redação do jornal The Whashington Post e demonstram-nos uma fração do que é o trabalho de um jornalista, como também é notório um grande afastamento entre eles, visto que ambos foram realizados em épocas cinematográficas bastante distintas.

Quanto aos méritos de utilizar o cinema como ferramenta de análise de discurso dos media:

Em suma, baseando na reflexão apresentada, podemos concluir que, através do cinema podemos apreender, aperfeiçoar e desenvolver conhecimentos em diversas áreas, como cultura, política, económica, social, entre outros, dependendo do modo cinematográfico que nos é apresentado.

Os próprios alunos rematam: «em suma fica a questão: até que ponto o cinema nos faz aprender?»

Na sequência dos dois visionamentos foi construído um «wiki», ferramenta de trabalho colaborativo online integrada na plataforma moodle, em que 
cada um contribuiu com pesquisas sobre o tema, aprofundando os seus conhecimentos e colocando em diálogo os seus pontos de vista sobre os filmes encontrados e o seu conteúdo. Entre alguns dos filmes apresentados e comentados estão Snowden, de Oliver Stone (2016), Verdade ou Mentira/Shatered Glass, de Billy Ray (2003, o jornalismo fraudulento), o Dossier Pelicano, de Alan J. Pakula (1993), Ligações Perigosas, de Kevin MacDonald (2009), Whisky Tango Foxtrot, de Glenn Ficarra e John Requa (a jornalista no cenário do Afeganistão) ou O Caso Spotlight, de Tom MacCarthy (2015) sobre o escândalo de pedofila na Igreja Católica.

Em conclusão, os estudantes praticaram as quatro dimensões da literacia mediática: aceder (aos dois filmes, que não conheciam, e à história das relações entre os dois media), compreender (o contexto dos factos, o papel da Imprensa na construção das democracias, produziram uma reflexão, pesquisaram sobre filmes sobre jornalismo), avaliar (os filmes como construtores de realidade, as investigações jornalísticas como criadores de agenda social - de formas distintas e significativas) e criar: produziram um wiki. De forma multimédia e colaborativa, na plataforma moodle, usando as ferramentas digitais.

A aquisição destas competências está em linha com a literatura, em particular quanto ao uso educativo dos media. No estudo feito para a ERC (Entidade Reguladora para a Comunicação Social), Pinto et al definem Educação para os Media como

o conjunto de processos, de conteúdos e de iniciativas tendentes a promover o uso esclarecido, a compreensão crítica e a atitude activa e criativa face à informação e aos media. Um trabalho a este nível envolve também o desenvolvimento de capacidades de produção, criação e expressão e a promoção de competências relacionadas com a pesquisa, selecção, análise, organização, contextualização e utilização da informação relevante para as situações do quotidiano e da participação da vida social. Nesse sentido, visa favorecer uma melhor comunicação e uma cidadania mais consciente e participativa. (Pinto et all, 2011, 148)

No Referencial de Educação para os Media dos dez «grandes princípios de Educação para os Media (Pereira et al, 2014, 10), destacamos o quarto:

Aquilo que os media produzem e disponibilizam aos seus públicos reflete, em alguma medida, a realidade social, mas é, sempre, sobretudo e necessariamente, uma interpretação dessa realidade. A interpretação não é forçosamente manipulação, mas uma forma de ver e de enunciar, ainda que pautada por critérios de rigor e de procura da verdade. Nesse sentido, é que se costuma dizer que os media constroem a realidade, na informação, mas igualmente na ficção, no entretenimento, na publicidade e na propaganda; não só nos media profissionais, mas também nos selfmedia, nos social media e nas redes sociais;

\section{Conclusões:}

O uso do cinema em contexto educativo tem uma tradição experimentada, com benefícios estudados em termos do processo de ensino/aprendizagem. Vários especialistas reportam como «oportunidades» factores como: favorecimento da interdisciplinaridade, por mobilizar um número e tipo muito diverso de matérias; promoção da aprendizagem activa, situando os estudantes como protagonistas da sua aprendizagem; valorização do trabalho cooperativo, diálogo e escuta activa; enriquecimento da ligação entre o mundo e a Escola, situando-a como um centro de redistribuição e produção cultural; desenvolvimento de competências pessoais como a atenção, observação, crítica e sensibilidade estética; despertar de uma reflexão profunda sobre as emoções (Aidelman e Colell 2018)

A sua articulação com a criação de uma literacia transmedia, entendida como

um conjunto de capacidades, práticas, valores, sensibilidades e estratégias de aprendizagem e intercâmbio desenvolvidas e aplicadas no contexto das novas culturas colaborativas (Scolari 2018)

enquadra-se nos desafios que a nova ecologia mediática pede ao ensino superior. Em particular, a integração da multimodalidade contemporânea implícita nos meios digitais interactivos no perfil de aprendizagem de estudantes que se querem prosumers críticos.

As sociedades multimediáticas contemporâneas pedem cidadãos capazes de aceder ao conhecimento, com pensamento crítico estruturado, mas também com criatividade reflexiva e participativa. Acreditamos que este caminho apenas tacteado poderá ser indicativo de abordagens mais complexas e frutuosas a desenvolver em futuras estratégias e experiências pedagógicas.

\section{Referências Bibliográficas}

Aidelman, N. e Colell, L. (2018). Transmitting Cinema: some proposals for our time. Film Education Journal, 1 (2). 147-162. Disponível em https://onedrive.live.com/?ci $\mathrm{d}=65 \mathrm{C} 32 \mathrm{~B} 816 \mathrm{BDD} 4 \mathrm{DD} 1 \& \mathrm{id}=65 \mathrm{C} 32 \mathrm{~B} 816 \mathrm{BDD} 4 \mathrm{DD} 1 \% 211$ 0306\&parld=65C32B816BDD4DD1\%219471\&o=OneUp, acedido a 02.05.2019

Bénard da Costa et all (1993). Jornalismo no Cinema. Lisboa: Cinemateca Portuguesa

Berger, Christa (Org.). O Jornalismo no Cinema. Porto Alegre: Editora da UFRGS, 2002.

Bernstein, C. (2004). "La meilleure version qu'on puisse obtenir de la vérité". Gosetti, G. e Frodon, J.M. (2004). Print the Legend. Locarno: Cahiers du Cinéma, Edipresse Publications SA

Cardoso, G. (2009), «Da Comunicação de Massa para a Comunicação em Rede» in Media, Redes e Comunicação - Futuros Presentes, Lisboa: Quimera Editores

Carvalho, Anabela (2000). "Opções Metodológicas em Análise de Discurso: Instrumentos, Pressupostos e Implicações". In Comunicação e Sociedade 2, Cadernos do Noroeste, Série Comunicação, Vol. 14 (1-2), pp 143-156. 
Comunicação da Comissão ao Parlamento Europeu, ao Conselho, ao Comité Económico e Social Europeu e ao Comité das Regiões: Uma Abordagem Europeia da Literacia Mediática no Ambiente Digital (COM 2007. 833).

Euromeduc (2009). Media Literacy in Europe: Controversies, Challenges and Perspectives. Bruxelas: Euromeduc.

European Association for Viewers Interests - EAVI (coord.) (2009). Study on Assessment Cri- teria for Media Literacy Levels. Final Report. Bruxelas: Comissão Europeia.

European Association for Viewers Interests - EAVI (coord.) (2011). Media Literacy: Testing and Refining Criteria to Access Media Literacy Levels in Europe. Final Report. Bruxelas: Comissão Europeia.

Fidalgo, António (2009). "Especificidade Epistemológica do Jornalismo". In Media, Redes e Comunicação - Futuros Presentes, Lisboa: Quimera Editores

Frodon, J.-M. (2004). "Depuis la nuit des temps". Gosetti, G. e Frodon, J.M. (2004). Print the Legend. Locarno: Cahiers du Cinéma, Edipresse Publications SA

Good, Howard (1989). Outcasts: the image of journalists in contemporary films. Londres:The Scarecrow Press

Gosetti, G. e Frodon, J.M. (2004). Print the Legend. Locarno: Cahiers du Cinéma, Edipresse Publications SA Jenkins, H. (2008), A Cultura da Convergência, S. Paulo: Editora Aleph

Kiarostami, Abbas (2004). "L'art du cinema s'enracine dans la réalité". Gosetti, G. e Frodon, J.M. (2004). Print the Legend. Locarno: Cahiers du Cinéma, Edipresse Publications SA

Kovach e Rosenstiel, B. e T. (2010). Blur: How to Know What is True in the Age of Information Overload, New York: Bloomsbury

Kovach e Rosenstiel, B. e T. (2004). O que os Elementos do Jornalismo: O que os Profissionais do Jornalismo Devem Saber e o Público Deve Exigir, Porto: Porto Editora

Livingstone, S. (2003). The changing nature and uses of media literacy. Media@lse Electronic Working Paper, 4.

Livingstone, S. (2004a). "Media literacy and the challenge of new information and communication technologies". In Communication Review, 7(1), 3-14.

Livingstone, S. (2004b). What is media literacy? Intermedia, 32(3), 18-20.

Livingstone, S. (2011). Media Literacy: Ambitions, Policies and Measures, Media@Ise. Martín-Barbero, J. (1997). Dos Meios às Mediações: Comunicação, Cultura e Hegemonia. Rio de Janeiro: Editora UFRJ.

Mahon, Bill (1994). Portrayal of Journalists in Movies. Editor \& Publisher, Oct. 1

Maia e Carmo, T. (2016). "Comunicar no século XXI Da crise dos media ao (novo) paradigma da comunicação digital". In Mátria Digital, $\mathrm{n}^{\circ} 4$, disponível em http:// matriadigital.cm-santarem.pt/images/numero4/teresa.pdf

MESQUITA, Mário (2013). O Estranho Dever do Cepticismo. Lisboa: Edições Tinta-da-China

Ness, Richard R. (2004). "Le film de journalisme: définition d'un genre". Gosetti, G. e Frodon, J.M. (2004). Print the Legend. Locarno: Cahiers du Cinéma, Edipresse Publications SA

NOGUEIRA, Lisandro. Cinema, jornalismo: lições para o ensino em sala de aula. In: $10^{\circ}$ Encontro Nacional de Professores de Jornalismo, Goiânia, 2007, Disponivel em:(http://www.fnpj.org.br/soac/ocs/viewpaper. php?id=65\&cf=1), consultado a 15.05.19

Peltzer, G. (1992). Jornalismo Iconográfico. Lisboa: Planeta Editora.
Pereira, Reinaldo Maximiano (2003). "O trabalho jornalístico como elemento de composição ficcional no cinema americano". In: XXVI Congresso Brasileiro de Ciências da Comunicação - INTERCOM. Belo Horizonte, 2003.

Pereira, S. et al (2014). Referencial de Educação para os Media para a Educação Pré-escolar, o Ensino Básico e o Ensino Secundário. Lisboa: Ministério da Educação e da Ciência

Pinto, M. et al (2011). Educação para os Media em Portugal: experiências, actores e contextos. Centro de Estudos de Comunicação e Sociedade da Universidade do Minho. Lisboa: ERC

Scolari, C. (2018). Literacia transmedia na nova ecologia mediática - Livro Branco. Barcelona: comissão Europeia

Thoman, E. \& Jolls, T. (2003). Literacy for the $21^{\text {st }}$ Century - An Overview \& Orientation Guide to Media Literacy Education. Santa Monica: Center for Media Literacy (CML).

Thoman, E. (2003). Skills and Strategies for Media Education. Santa Monica: Center for Media Literacy (CML). Toffler, A. (1980). A Terceira Onda. Rio de Janeiro: Record. 